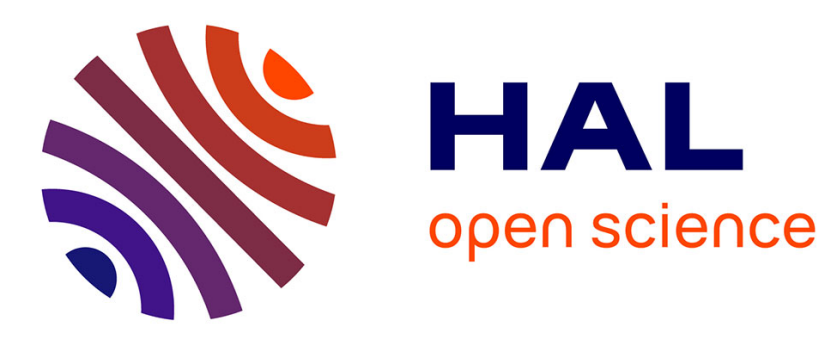

\title{
Glycerol Boosted Rh-Catalyzed Hydroaminomethylation Reaction: A Mechanistic Insight
}

\author{
Alejandro Serrano-maldonado, Trung Dang-bao, Isabelle Favier, Itzel \\ Guerrero-ríos, Daniel Pla, Montserrat Gómez
}

\section{- To cite this version:}

Alejandro Serrano-maldonado, Trung Dang-bao, Isabelle Favier, Itzel Guerrero-ríos, Daniel Pla, et al.. Glycerol Boosted Rh-Catalyzed Hydroaminomethylation Reaction: A Mechanistic Insight. Chemistry - A European Journal, 2020, 26 (55), pp.12553-12559. 10.1002/chem.202001978 . hal-03011334

\section{HAL Id: hal-03011334 https://hal.science/hal-03011334}

Submitted on 18 Nov 2020

HAL is a multi-disciplinary open access archive for the deposit and dissemination of scientific research documents, whether they are published or not. The documents may come from teaching and research institutions in France or abroad, or from public or private research centers.
L'archive ouverte pluridisciplinaire HAL, est destinée au dépôt et à la diffusion de documents scientifiques de niveau recherche, publiés ou non, émanant des établissements d'enseignement et de recherche français ou étrangers, des laboratoires publics ou privés. 


\title{
Glycerol boosted Rh-catalyzed hydroaminomethylation reaction, a mechanistic insight
}

\author{
Alejandro Serrano-Maldonado, ${ }^{[a]}$ Trung Dang-Bao, ${ }^{\delta[b]}$ Isabelle Favier, ${ }^{[b]}$ Itzel Guerrero-Ríos, ${ }^{*[a]}$ Daniel \\ $\mathrm{Pla},{ }^{*[\mathrm{~b}]}$ and Montserrat Gómez ${ }^{*[\mathrm{~b}]}$
}

Dedicated to the memory of Prof. Erika Martin (1963-2017)

[a] A. Serrano-Maldonado, Prof. I. Guerrero-Ríos

Departamento de Química Inorgánica, Facultad de Química

Universidad Nacional Autónoma de México

Av. Universidad 3000, 04510 CDMX, Mexico

E-mail: itzelgr@unam.mx

[b] T. Dang-Bao, Dr. I. Favier, Dr. D. Pla, Prof. M. Gómez Laboratoire Hétérochimie Fondamentale et Appliquée

Université Toulouse 3 - Paul Sabatier, CNRS UMR 5069

118 route de Narbonne, 31062 Toulouse Cedex 9, France

E-mail:pla@lhfa.fr, gomez@chimie.ups-tlse.fr

$\S \quad$ Current address: Faculty of Chemical Engineering

Ho Chi Minh City University of Technology, VNU-HCM

268 Ly Thuong Kiet, District 10, Ho Chi Minh City, Vietnam

Supporting information for this article is given via a link at the end of the document and contains a general experimental section, optimization data, control tests, reaction monitoring and characterization data of selected organic compounds $\left({ }^{1} \mathrm{H}\right.$ and $\left.{ }^{13} \mathrm{C} N M R, M S\right)$.

\begin{abstract}
In this contribution, we report a Rh-catalyzed hydroaminomethylation reaction of terminal alkenes in glycerol that proceeds efficiently under mild conditions to produce the corresponding amines in relatively high selectivity towards linear amines, moderate to excellent yields using a low catalyst loading (1 mol\% [Rh], 2 mol\% phosphine) and relative low pressure $\left(\mathrm{H}_{2} / \mathrm{CO}, 1: 1\right.$, total pressure $\left.10 \mathrm{bar}\right)$. This work sheds light on the importance of glycerol in enabling enamine reduction via hydrogen transfer. Moreover, the crucial role of $\mathrm{Rh}$ as chemoselective catalyst in the condensation step has been evidenced for the first time in the frame of the hydroaminomethylation reaction by precluding deleterious aldol condensation reactions. The hydroaminomethylation proceeds under a molecular regime; the outcome of catalytically active species into metal-based nanoparticles renders the catalytic system inactive.
\end{abstract}

\section{Introduction}

Among nitrogen compounds, amines play an important role as feedstock chemicals with a production on million-ton scale annually in the synthesis of agrochemicals, pharmaceuticals, solvents, dyes, monomers for polymerizations and functional materials, among the most important applications. ${ }^{[1]}$ Despite the production of amines often requires expensive and sometimes toxic substances through conventional methods, hydroaminomethylation (HAM) of alkenes offers an alternative synthesis from an environmental and economic point of view. ${ }^{[2]}$ HAM is a multi-component tandem transformation that consists of three consecutive steps: the metal-catalyzed hydroformylation of an alkene, followed by condensation of the resulting aldehyde with an amine leading to an enamine (or imine/iminium) intermediate that undergoes metal-catalyzed hydrogenation, giving water as the only concomitant product. ${ }^{[2 \mathrm{a}-\mathrm{g}, 3]}$ HAM is very attractive from an atom economy viewpoint, however it often requires harsh conditions, in particular using $\mathrm{Rh}$-based systems, ${ }^{[2 a-g]}$ despite its well-known ability to catalyze hydroformylation processes. ${ }^{[4]}$ In order to overcome this drawback, it is essential to design catalytic systems able to promote both hydroformylation and hydrogenation steps under relative mild conditions. In the literature, this approach has been considered and systems involving two catalysts have been described. Actually, Xiao ${ }^{[5]}$ and $\mathrm{Han}^{[6]}$ have employed a Rhbased catalyst together with an optically pure phosphoric acid as organocatalyst promoting imine hydrogenation towards the synthesis of chiral secondary amines, from styrene and aniline derivatives under mild conditions (total pressure: $2-11$ bar; 25 $-50{ }^{\circ} \mathrm{C} ; 16-72 \mathrm{~h}$ ). For the synthesis of linear amines, Beller and coworkers reported a catalytic system constituted by $\mathrm{Rh}(\mathrm{I})$ and $\operatorname{Ir}(\mathrm{I})$ precursors (Ir/Rh ratio ca. 10/1) in the presence of an excess of TPPTS, taking advantage of the known performance of Ir-based systems in the hydrogenation of imines and enamines, ${ }^{[7]}$ leading to primary amines from terminal alkenes and ammonia (total pressure 78 bar; $110-130{ }^{\circ} \mathrm{C} ; 5-10 \mathrm{~h}$ ) with high regioselectivity (linear amines) and good chemoselectivity (primary amines) (Scheme 1a). ${ }^{[8]}$ More recently, Hartwig's group has also reported a Rh/lr catalytic system constituted by $\left[\mathrm{Rh}(\mathrm{acac})(\mathrm{CO})_{2}\right] / \mathrm{BISBI} \quad\left(\mathrm{BISBI}=2,2^{\prime}-\right.$ bis(diphenylphosphinomethylene)-1,1'-biphenyl) and Xiao's catalyst, an Ir(III) organometallic complex stable in the presence of carbon monoxide; ${ }^{[9]}$ this catalytic system permits to work under milder conditions (total pressure 3.4 bar; $80{ }^{\circ} \mathrm{C}$; $20 \mathrm{~h}$ ), producing secondary linear amines from good to high yields, using a mixture of solvents (toluene/methanol) and an aqueous buffer solution of $\mathrm{NaHCO}_{2}$ (Scheme 1b). Notably, the role of bidentate ligands, such as the diphosphine BISBI, has proven to be key for such high regioselectivities. ${ }^{[10]}$ 
Based on these precedents and taking into account the properties of glycerol as solvent in a wide range of transformations, ${ }^{[11]}$ mainly involving metal-catalyzed homogeneous processes, ${ }^{[12]}$ but also metal nanoparticles ${ }^{[13],[14]}$ and catalyst-free reactions, ${ }^{[15]}$ we envisaged to explore the role of glycerol as hydrogen donor in the HAM reaction of terminal olefins catalyzed by $\left[\mathrm{Rh}(\mathrm{acac})(\mathrm{CO})_{2}\right] /$ TPPTS system through enhancing the reductive amination, which often is the rate limiting step of the HAM reaction (Scheme 1c). ${ }^{[16]}$ This contribution aims to provide a mechanistic insight, in particular related to the role of rhodium in the amine/aldehyde condensation step and the hydrogenation of the resulting enamine, in glycerol under mild reaction conditions.

a) Beller 1999

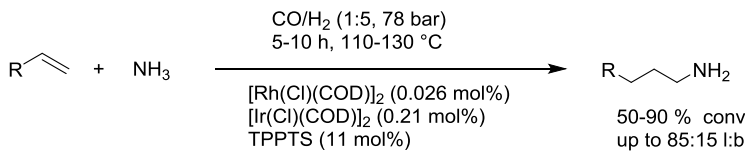

b) Hartwig 2019

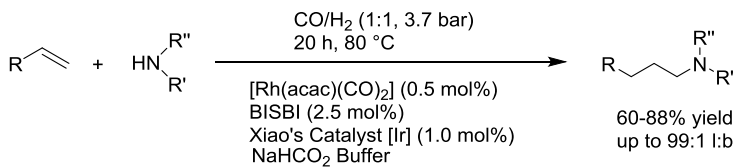

c) This work

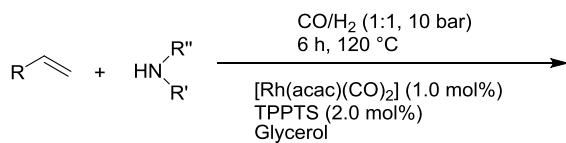

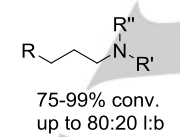

Scheme 1. Strategies to conduct the multi-step HAM reaction under tailored conditions for the synthesis of primary amines.

\section{Results and Discussion}

Based on the established HAM mechanism, terminal alkenes are initially transformed into the corresponding linear and branched aldehydes by hydroformylation, which then react with an amine to produce the corresponding enamine by a condensation reaction. Hydrogenation of these latter intermediates affords the expected amines, provided that sidereactions such as alkene isomerization or hydrogenation are precluded (Scheme 2, illustrating the case of oct-1-ene and morpholine).

We chose the HAM reaction of oct-1-ene (1) and morpholine (a) catalyzed by $\left[\mathrm{Rh}(\mathrm{acac})(\mathrm{CO})_{2}\right] /$ TPPTS in glycerol as benchmark reaction (Scheme 2). Under optimized conditions, high chemoselectivity was obtained towards the formation of amines 1a at $120^{\circ} \mathrm{C}$ and 10 bar (total pressure) of an equimolar $\mathrm{CO}: \mathrm{H}_{2}$ mixture, only observing minor alkene isomerization (less than $10 \%$; see entry 1 in Table 1). Notably, the use of the diphosphine BISBI instead of TPPTS exhibited lower reactivity (50\% conversion) and no selectivity enhancement (I-1a / b-1a, $70 / 30$ ). The reaction optimization survey in terms of temperature pressure, time, Rh/phosphine ratio and solvent (for further details, see Tables S1 and S2 in the Supporting Information) raised concerns on crucial solvent effects that merit a special discussion.

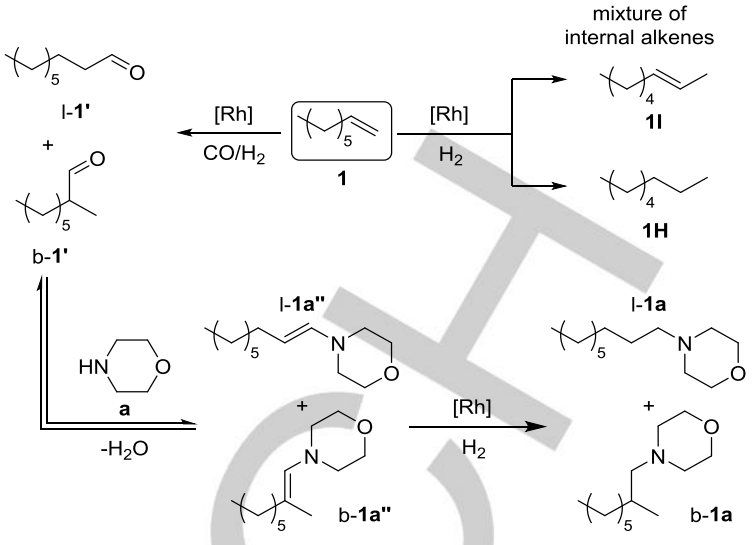

Scheme 2. Hydroaminomethylation benchmark reaction of Rh-catalyzed oct1-ene (1) and morpholine (a). By-products from $\mathbf{1}$ are also indicated $(\mathbf{1 H}$ and 1I).

When toluene or dioxane were used, full conversion was observed (entries 2 and 3, Table 1), showing moderate chemoselectivity towards the HAM product due to competing olefin isomerization (mixture of internal alkenes) and substrate hydrogenation, albeit regioselectivity was similar for both solvents, leading to ca. 3:2 linear to branched ratio of $\mathbf{1 a}$. Despite the high conversion and high chemoselectivity towards the formation of amines obtained in cyclopentyl methyl ether (CPME), the reaction was not regioselective (entry 4, Table 1). Given the reported efficiency of alcohols in promoting HAM reactions, ${ }^{[17]}$ we sought to evaluate the effect of other protic solvents than glycerol. Whereas the use of water (entry 5, Table 1) led to an inactive catalytic system, both $\mathrm{MeOH}$ and butan-1-ol presented higher olefin isomerization (entries 6 and 7, Table 1) than glycerol (entry 1, Table 1). Thus, glycerol provided the best results in terms of chemo- and regioselectivity towards the formation of $\mathbf{1 a}$, outperforming both non-protic and other protic solvents in terms of deleterious olefin isomerization/hydrogenation side-reactions.

\begin{tabular}{|c|c|c|c|c|c|c|c|}
\hline \multirow{2}{*}{ Entry } & \multirow{2}{*}{ Solvent } & \multirow{2}{*}{$\begin{array}{l}\text { Conv. } \\
(\%)^{[b]}\end{array}$} & \multicolumn{5}{|c|}{ Selectivity $^{[\mathrm{b}]}$} \\
\hline & & & $11(\%)$ & $1 \mathrm{H}(\%)$ & 1a"'(\%) & $1 \mathrm{a}(\%)$ & I-1a/b-1a \\
\hline 1 & Glycerol & 95 & 7 & nd & nd & 93 & $80 / 20$ \\
\hline 2 & Toluene & 98 & 21 & 23 & nd & 56 & $65 / 35$ \\
\hline 3 & Dioxane & 99 & 26 & 14 & nd & 60 & $66 / 34$ \\
\hline 4 & CPME & $>99$ & nd & nd & nd & 95 & $50 / 50$ \\
\hline 5 & $\mathrm{H}_{2} \mathrm{O}$ & $<5$ & nd & nd & nd & nd & nd \\
\hline 6 & $\mathrm{MeOH}$ & 99 & 19 & nd & nd & 81 & $70 / 30$ \\
\hline 7 & Butan-1-ol & $>99$ & 26 & nd & nd & 73 & $70 / 30$ \\
\hline
\end{tabular}

Table 1. Rh-catalyzed HAM of oct-1-ene and morpholine in different solvents. ${ }^{[\mathrm{a]}]}$

[a] General conditions: $1 \mathrm{mmol}$ of 1 -octene, $1.5 \mathrm{mmol}$ of morpholine, $1 \mathrm{~mol} \%$ [Rh(acac)(CO) $)_{2}$, 2 mol\% TPPTS, $2 \mathrm{~mL}$ of solvent, 5 bar $\mathrm{CO} / 5$ bar $\mathrm{H}_{2}$ (pressure at room temperature), $120{ }^{\circ} \mathrm{C}, 6 \mathrm{~h}$; nd = not determined; see Scheme 2 for the labelling of compounds. [b] Conversion, selectivity and 
linear/branched ratio were determined by GC employing $n$-dodecane as internal standard. [c] Carried out at $80^{\circ} \mathrm{C}$. [d] $8 \%$ of aldehyde $1 \mathrm{a}^{\prime}$ detected by GC-MS.

Taking into account the remarkable effect of glycerol and given the fact that hydrogenation of the imine-, iminium- or enaminetype intermediates is generally accepted as the rate determining step for Rh-catalyzed HAM, ${ }^{[2 a, 18]}$ we considered that a hydrogen transfer (glycerol as reducing agent) could be operative in addition to the hydrogenation reaction, ${ }^{[11 e]}$ enabling low pressure conditions while overriding the need for a metal-based cocatalyst. $^{[9]}$ Thus, the nature of the hydrogen donor was further assessed with glycerol and butan-1-ol at $80 \stackrel{\circ}{ } \mathrm{C}$, revealing that enamine reduction was faster in the latter albeit with moderate 1a selectivity (entries 1 and 2, Table 2). The effect of glycerol in boosting enamine reduction was observed when a solvent mixture of glycerol and butan-1-ol (0.25:0.75) was used, yielding a quantitative conversion and full chemoselectivity towards $\mathbf{1 a}$, showing a slight decrease in terms of regioselectivity (entries 1 and 2 vs 3 , Table 2).

Table 2. Rh-catalyzed enamine reduction studies of oct-1-ene and morpholine benchmark reaction in glycerol, butan-1-ol and a mixture of both. ${ }^{[a]}$

\begin{tabular}{cccccc}
\hline Entry & $\begin{array}{c}\text { Solvent } \\
\text { (glycerol:butan-1-ol) }\end{array}$ & $\begin{array}{c}\text { Conv. } \\
(\%)^{\mathrm{b}}\end{array}$ & 1a"'(\%) $^{\text {1a }}$ & 1a (\%) & I-1a/b-1a \\
\hline 1 & $1: 0$ & 76 & 42 & $50^{\mathrm{c}}$ & $84 / 16$ \\
2 & $0: 1$ & $>99$ & 41 & $51^{\mathrm{d}}$ & $84 / 16$ \\
3 & $0.25: 0.75$ & $>99$ & nd & $>99$ & $70 / 30$ \\
\hline
\end{tabular}

[a] General conditions: $1 \mathrm{mmol}$ of 1 -octene, $1.5 \mathrm{mmol}$ of morpholine, $1 \mathrm{~mol} \%$ of [Rh(acac) $(\mathrm{CO})_{2}$ ], $2 \mathrm{~mol} \%$ of TPPTS, $2 \mathrm{~mL}$ of solvent, $\mathrm{CO}$ (5 bar) $/ \mathrm{H}_{2}$ (5 bar), $80^{\circ} \mathrm{C}, 6 \mathrm{~h}$; see Scheme 2 for the labelling of compounds. [b] Conversion, selectivity and linear/branched ratios were determined by GC employing $n$ dodecane as internal standard; nd, not determined. [c] $8 \%$ of aldehyde 1a' detected by GC-MS. [d] 7\% of aldehyde 1a' detected by GC-MS

With the aim of evidencing the plausible role of glycerol as reducing agent, the reaction of $4-[(E)$-non-1-en-1-yl]morpholine intermediate $\left(\mathbf{I}-\mathbf{1 a} \mathbf{a}^{\prime}\right)^{[19]}$ in glycerol under inert atmosphere, i.e. in the absence of molecular $\mathrm{H}_{2}$, was carried out (Scheme $3 \mathrm{a}$ ). Interestingly, up to $67 \%$ conversion of I-1a" to I-1a was obtained. This reactivity was confirmed by the hydrogen transfer of a tertiary enamine such as 4-(1-cyclohexen-1-yl)morpholine, yielding full conversion towards 4-cyclohexylmorpholine (Scheme 3b). Despite the ability of glycerol to reduce enamines, ${ }^{[20]}$ |-1a" was only slightly reduced in the absence of catalyst (less than $5 \%$ ), proving that enamine hydrogen transfer is catalyzed by rhodium.

(a)

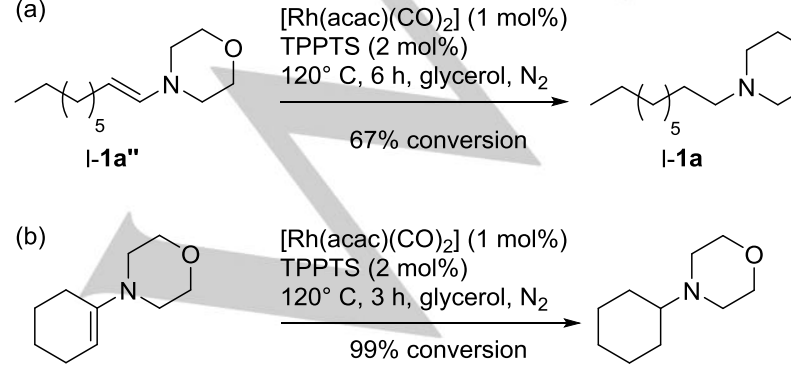

Scheme 3. Rh-catalyzed hydrogen transfer reaction of 4-[(E)-non-1-en-1yl]morpholine (a) and 4-(1-cyclohexen-1-yl)morpholine (b) in glycerol (for ${ }^{1} \mathrm{H}$ NMR crude analysis, see Figure $\mathrm{S} 1$ in the Supporting Information).

We next investigated whether the in-situ generated aldehydes in the initial hydroformylation step of the HAM process could also undergo hydrogen transfer processes under the optimized reaction conditions. Thus, a control test with nonanal (I-1') was carried out but no formation of nonan-1-ol was observed; alternatively, acetals from the reaction of the aldehyde and glycerol were obtained, because acetalization is probably faster than hydrogen transfer reaction. ${ }^{[21]}$

We then focused on the reactivity of aldehydes towards enamine formation and subsequent reduction to give the desired amine products, while avoiding aldol condensation pathways (Table 3 ). Accordingly, the following control tests were carried out. First, the condensation between nonanal (I-1') and morpholine (a) using a 1/1.5 molar ratio of reagents under inert atmosphere at $120{ }^{\circ} \mathrm{C}$ in the presence of catalyst, afforded full conversion but mainly yielding the aldol condensation product $(62 \%)$ together with only $38 \%$ of the desired $\mathrm{I}-1 \mathrm{a}$ product (coming from the reduction of enamine $\mathbf{1 - 1 a "}$ " by glycerol as discussed above; entry 1 , Table 3 ). Under $\mathrm{H}_{2} / \mathrm{CO}$ pressure, the formation of I-1a was slightly improved (entry 2, Table 3 ). However, in the absence of catalyst, the aldol product was favored (up to $88 \%$; entry 3 , Table 3 ), indicating the benefic role of the Rh/TPPTS system in terms of chemoselectivity.

The selectivity towards the desired amine substantially enhanced when a large excess of morpholine was used (I-1'/a ratio of $0.1 / 3$ ), leading up to $71 \%$ of $\mathrm{I}-1$ a (entry 4 , Table 3 ). These latter conditions, but under $\mathrm{H}_{2} / \mathrm{CO}$ pressure, gave $98 \%$ of I-1a (entry 5, Table 3); in the absence of catalyst, aldol condensation products were obtained up to $49 \%$ yield (entry 6 , Table 3 ), in agreement with the trend observed using a lower excess of morpholine (entry 3 , Table 3 ). These results proved that both a low concentration of aldehyde (probably shifting the equilibrium towards the formation of enamine I-1a" by the amine excess) and the presence of the rhodium catalyst are necessary in order to prevent the formation of aldol condensation products as well as the reducing effect of glycerol facilitating the enamine reduction. Consequently, under catalytic conditions, the condensation step must be fast enough to avoid the accumulation of aldehydes throughout reaction; in this step, rhodium plays a crucial role in the chemoselectivity, hampering the formation of aldol condensation products. This reactivity behavior was corroborated by the GC-MS monitoring of the benchmark reaction under catalytic conditions (see below).

Table 3. Reductive amination controls in glycerol. ${ }^{[\mathrm{a}]}$

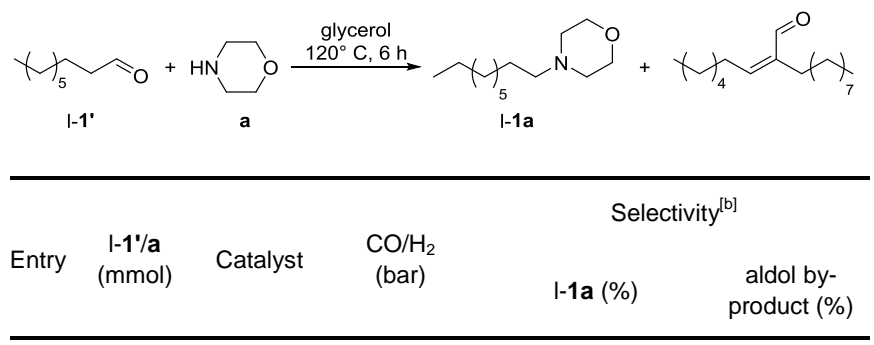




\begin{tabular}{cccccc}
\hline 1 & $1.0 / 1.5$ & Yes & $0 / 0$ & 38 & 62 \\
2 & $1.0 / 1.5$ & Yes & $5 / 5$ & 49 & 51 \\
3 & $1.0 / 1.5$ & Non & $5 / 5$ & $7^{[\mathrm{cc}}$ & 88 \\
4 & $0.1 / 3.0$ & Yes & $0 / 0$ & $71^{[\mathrm{d}]}$ & n.d. \\
5 & $0.1 / 3.0$ & Yes & $5 / 5$ & 98 & 2 \\
6 & $0.1 / 3.0$ & Non & $5 / 5$ & 51 & $49^{[\mathrm{d}]}$ \\
\hline
\end{tabular}

[a] General conditions: nonanal ( $\left(-\mathbf{1}^{\prime}\right)$, morpholine (a), $1 \mathrm{~mol} \%$ of $\left[\mathrm{Rh}(\mathrm{acac})(\mathrm{CO})_{2}\right]$ and $2 \mathrm{~mol} \%$ of TPPTS unless otherwise noted, $2 \mathrm{~mL}$ of glycerol, $\mathrm{CO}(5 \mathrm{bar}): \mathrm{H}_{2}(5 \mathrm{bar})$ unless otherwise noted, $120^{\circ} \mathrm{C}, 6 \mathrm{~h}$; see Table S3 in the Supporting Information for full details. [b] Conversion (full conversion observed for the experiments indicated in the table), chemo- and regio-selectivity were determined by ${ }^{1} \mathrm{H}$ NMR and GC using $n$-dodecane as internal standard; n.d., not determined. [c] $5 \%$ of the enamine I-1a" was observed. [d] $71 \%$ conversion. [d] The aldol condensation product $(35 \%)$ further condenses with morpholine to yield a by-product in $14 \%(\mathrm{~m} / \mathrm{z} 335)$.

Despite high pressures are usually required for hydroaminomethylation, ${ }^{[4 b, 4 c]}$ the methodology described herein permitted to work under relative low pressure. Notably, in the absence of morpholine, the hydroformylation of oct-1-ene towards I-1' and b-1' in glycerol only worked under high pressure ( 25 bar $\mathrm{H}_{2}$ / 25 bar $\mathrm{CO}$ ), favoring the formation of the branched regioisomer (I-1'/b-1' ratio of $36 / 64$, see Table S4 in the Supporting Information). Thus, this behavior suggests that the amine is involved in the hydroformylation step, ${ }^{[4 \mathrm{~b}, 22]}$ probably by coordination to the rhodium center, modifying the energy of intermediates and transition states ${ }^{[23]}$ and in consequence influencing the rate and selectivity of the hydroformylation reaction. ${ }^{[24]}$

In order to assess the organic compounds present throughout the HAM reaction, reaction monitoring studies were performed by GC-MS and FTIR (Figure 1 and Figure S3 in the Supporting Information, respectively). The GC-MS study evidenced that the aldehyde intermediates (I-1' and b-1') arising from olefin hydroformylation, were present at rather low concentrations throughout the reaction in agreement with the behavior observed for the condensation step (see above). Thus, after $30 \mathrm{~min}$ of reaction, the molar fraction of enamine intermediates $1 \mathbf{a}^{\prime \prime}$ is consistently higher than the corresponding aldehyde precursors $\mathbf{1}^{\prime}$, indicating that the reduction of the former represents the ratedetermining step for the overall HAM reaction. Despite the operando FTIR method did not permit the detection of organometallic intermediates or aldehydes under catalytic conditions due to their low concentration (see Figure S3 in the Supporting Information), the reaction profiles of oct-1-ene (1) conversion (disappearance of the $\mathrm{C}=\mathrm{C}$ stretching band at 1641 $\mathrm{cm}^{-1}$ ), together with the presence of a transient enamine intermediate 1a" (967 $\mathrm{cm}^{-1}$ band formation and decay) and the formation of the amine 1a (C-N stretching band at $1031 \mathrm{~cm}^{-1}$ increase) are consistent with GC monitoring data (Figure 1) and ${ }^{1} \mathrm{H}$ NMR analysis of the reaction mixture after the $24 \mathrm{~h}$ operando FTIR monitoring (see Figure S4 in the Supporting Information; for a control FTIR monitoring, see Figure S5).

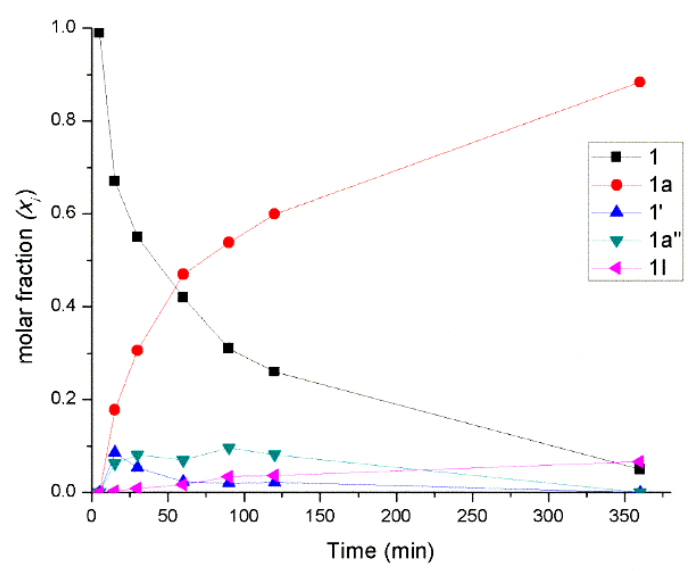

Figure 1. Monitoring by GC-MS of the hydroaminomethylation of oct-1-ene (1) and morpholine (a) catalyzed by Rh(I)/TPPTS catalyst in glycerol. Reaction conditions: $1 \mathrm{mmol}$ of $\mathbf{1}, 1.5 \mathrm{mmol}$ of a, $1 \mathrm{~mol} \%$ of [Rh(acac)(CO) $\left.)_{2}\right], 2 \mathrm{~mol} \%$ of TPPTS, $2 \mathrm{~mL}$ of glycerol, $\mathrm{CO}(5 \mathrm{bar}) / \mathrm{H}_{2}$ (5 bar), $120{ }^{\circ} \mathrm{C}$. Molar fraction of products $\left(\mathrm{x}_{\mathrm{i}}\right)$ was determined by $\mathrm{GC}$ using $n$-dodecane as internal standard. For detailed data, see Table S5 in the Supporting Information.

Alternative mechanistic HAM approaches consisting on the direct C-C coupling of oct-1-ene with 4,4'methylenedimorpholine aminal, $\mathrm{N}$-formylmorpholine or $\mathrm{N}$ (methylene)morpholinium chloride did not work under the optimized reaction conditions. Despite Rh nanoparticles were detected after the reaction by TEM (see Figure S6 in the Supporting Information), preformed $\mathrm{Rh}$ nanoparticles were totally inactive in the HAM benchmark reaction (see Figure S7 in the Supporting Information), indicating that hydroaminomethylation operates under a molecular regime.

Table 4. Reaction scope of Rh-catalyzed HAM in glycerol. ${ }^{[a]}$
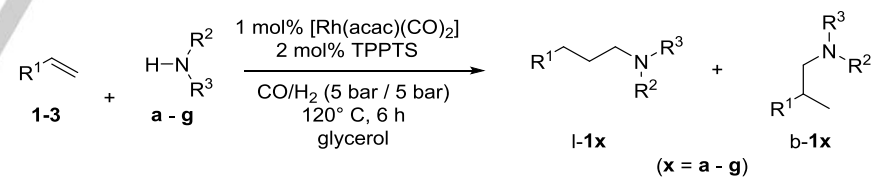

\begin{tabular}{|c|c|c|c|c|c|}
\hline \multirow{2}{*}{ Entry } & \multirow{2}{*}{ Alkene } & \multirow{2}{*}{ Amine } & \multirow{2}{*}{$\begin{array}{l}\text { Conv. } \\
(\%)^{[b]}\end{array}$} & \multicolumn{2}{|c|}{ Selectivity ${ }^{[\mathrm{b}]}$} \\
\hline & & & & $1 \times(\%)^{[c]}$ & $\mid-1 x / b-1 x$ \\
\hline
\end{tabular}

2 (n.d.)




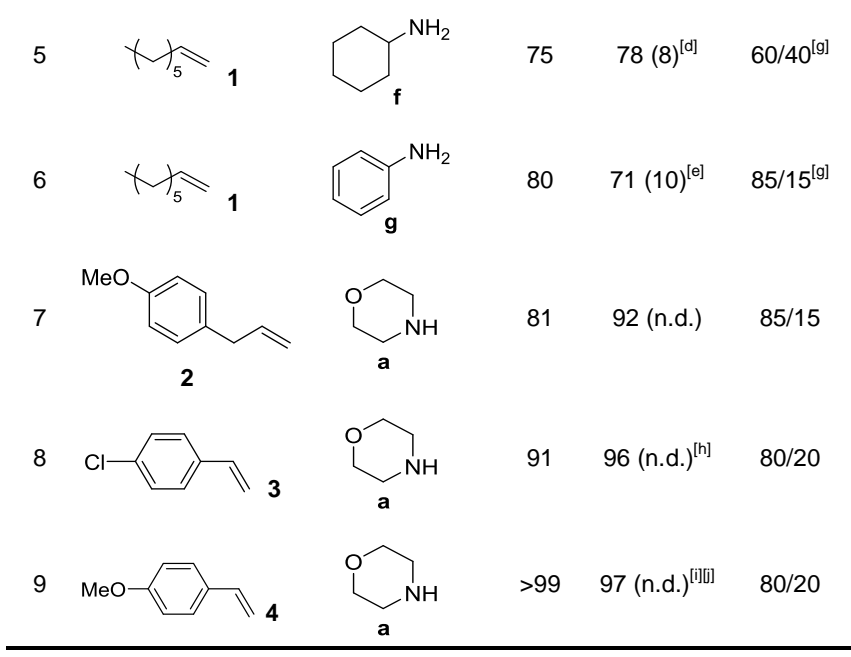

[a] General conditions: $1 \mathrm{mmol}$ of alkene $(\mathbf{1}-\mathbf{4}), 1.5 \mathrm{mmol}$ of amine $(\mathbf{a}-\mathbf{g}), 1$ $\mathrm{mol} \%$ of $\left[\mathrm{Rh}(\mathrm{acac})(\mathrm{CO})_{2}\right], 2 \mathrm{~mol} \%$ of TPPTS, $2 \mathrm{~mL}$ of glycerol, 5 bar CO / 5 bar $\mathrm{H}_{2}$ (pressure at room temperature), $120^{\circ} \mathrm{C}, 6 \mathrm{~h}$. [b] Conversion, chemoand regio-selectivity were determined by GC using $n$-dodecane as internal standard. [c] In brackets, percentage of internal alkenes from oct-1-ene. [d] $14 \%$ of tertiary amine was formed. [e] $19 \%$ of tertiary amine was formed. [f] Linear/branched ratio determined by ${ }^{1} \mathrm{H}$ and ${ }^{13} \mathrm{C}$ NMR. [g] Linear/branched for the tertiary amine was not determined. [h] 4\% 4-chloroethylbenzene. [i] 3\% 4ethylanisole. [i] Reaction conditions: $1 \mathrm{mmol}$ of 4 -vinylanisole, $1.5 \mathrm{mmol}$ of morpholine, $1 \mathrm{~mol} \%$ [Rh(acac)(CO) $)_{2}$ ], $1 \mathrm{~mol} \%$ of TPPTS in $2 \mathrm{~mL}$ of glycerol, 5 bar $\mathrm{CO} / 15$ bar $\mathrm{H}_{2}$ (pressure at room temperature), $120^{\circ} \mathrm{C}, 10 \mathrm{~h}$.

With the optimized experimental conditions for the benchmark reaction, the HAM reaction scope was evaluated using primary and secondary amines, including aniline derivatives $(\mathbf{a}-\mathbf{g})$, as well as different terminal alkenes $(\mathbf{1}-\mathbf{4})$ giving high conversions towards the expected products ( $75-94 \%$ conversion, Table 4$)$. Concerning chemoselectivity, for secondary amines, the expected amine product was mainly obtained (entries $1-4$, Table 4). However, with cyclohexylamine and aniline (entries 5-6, Table 4), ca. $15-20 \%$ of tertiary amine was formed together with the expected secondary amine products, due to the highest reactivity of secondary amines, thus competing with the primary amine substrates. Modifying the ratio oct-1-ene/aniline (1/0.5, $1 / 1.5,1 / 2)$, the selectivity was not improved; as expected, a higher amount of aniline favored the formation of bis(octyl)phenyl amine (up to 33\%, see Table S6 in the Supporting Information).

Concerning regioselectivity, the linear isomer was the major product in all cases, with a maximum $\mathrm{l} / \mathrm{b}$ ratio of $85 / 15$ (entries 5 and 7, Table 4). Ammonia-based reagents $\left(\mathrm{NH}_{3}(\mathrm{aq}), \mathrm{NH}_{4} \mathrm{OAc}\right)$ and sulfonamide derivatives (methylsulfonamide, $p$ tolylsulfonamide) did not react under these reaction conditions. Unfortunately, di- and trisubstituted alkenes (cyclooctene, ethyloleate, $\alpha$-pinene, $\alpha$-methylstyrene, 4-octene, limonene) did not undergo HAM (conversions lower than $20 \%$, see Table S7 in the Supporting Information).

Furthermore, aryl-substituted alkenes, such as 4-allylanisole (2), 4-chlorostyrene (3) and 4-methoxystyrene (4) showed good to excellent conversions towards HAM, together with high linear-tobranched outcomes (entries 7-9, Table 4). These results are particularly interesting for styrene derivatives, because the formation of the branched regioisomer in the Rh-catalyzed hydroformylation step is generally favored; ${ }^{[2 a]}$ however, the nature of ligand and solvent triggers a non-innocent effect on the regioselectivity, reversing this trend as proven by Zhang's group; they obtained the best linear/branched ratio using a tetraphosphorus-based ligand and tert-amyl alcohol as solvent. ${ }^{[25]}$

\section{Conclusion}

This contribution sheds light on the mechanism of multi-step Rhcatalyzed hydroaminomethylation in glycerol. For the benchmark reaction (oct-1-ene and morpholine as reagents), we evidenced paramount solvent effects in the reactivity of Rh-based catalytic systems, revealing the role of glycerol as reducing agent. Actually, we demonstrated that both Rh-catalyzed hydrogenation and hydrogen transfer processes cooperate to favor enamine reduction under relative low pressure ( 5 bar $\mathrm{H}_{2} / 5$ bar $\mathrm{CO}$ ). Moreover, we have shown that the enamine formation proceeds via a chemoselective condensation promoted by rhodium; under these conditions aldol reactions are precluded in contrast to the non-catalyzed organic condensation. The results described herein highlight both the fast rhodium-promoted condensation of the aldehyde with the amine to selectively form the enamine intermediate, as well as the role of glycerol as a hydrogen transfer agent, boosting the Rh-catalyzed reduction of this transient enamines and thus permitting to work at relative low pressure.

The reaction scope of terminal alkenes and amines showed the versatility of the process exhibiting excellent chemoselectivity towards the formation of secondary and tertiary amines, with high linear-to-branched regioselectivity, including styrene derivatives (up to 85:15).

Overall, the results reported herein stress the fact that glycerol enables a Rh-based catalytic system working under molecular regime, to perform one-pot HAM cascade reaction to reach a reactivity behavior that was thus far limited to multi-catalytic systems, ${ }^{[5-6,8-9]}$ in particular those based on $\mathrm{Rh} / \mathrm{Ir}$ bimetallic catalysts for the synthesis of linear amines. ${ }^{[9]}$

\section{Experimental Section}

General procedure for catalytic hydroaminomethylation. In a stainless steel reactor vessel $(100 \mathrm{~mL})$ were placed the desire amount of $\left[\mathrm{Rh}(\mathrm{acac})(\mathrm{CO})_{2}\right]$ and tris(3-sulfophenyl)phosphine trisodium salt (TPPTS) together with glycerol $(2 \mathrm{~mL})$, the selected olefin $(1 \mathrm{mmol})$, the selected secondary or primary amine $(1.5 \mathrm{mmol})$ and $n$-dodecane as internal standard $(1 \mathrm{mmol})$. The reactor was pressurized with the selected proportion of $\mathrm{CO} / \mathrm{H}_{2}$ at the desire pressure, temperature and time. After the reaction was completed, the reactor vessel was cooled to room temperature and consecutively depressurized. Products were extracted with cyclohexane $(5 \times 3 \mathrm{~mL})$, filtered through a Celite column and analyzed by gas chromatography to determine conversion and selectivity. Products were isolated and characterized by ${ }^{1} \mathrm{H}$ and ${ }^{13} \mathrm{C} \mathrm{NMR}$, and MS. The Rh content of extracted organic products was in the range of 0.01 . $0.08 \mathrm{ppm}$ as determined by ICP-AES analyses.

Synthesis of Rh nanoparticles. In a Fisher-Porter bottle, [Rh(acac) $\left.(\mathrm{CO})_{2}\right](13.0 \mathrm{mg}, 0.05 \mathrm{mmol})$ and TPPTS (28.5 mg, $\left.0.05 \mathrm{mmol}\right)$ were dissolved in $10 \mathrm{~mL}$ of glycerol at room temperature under Ar. The system was then pressurized with 3 bar of $\mathrm{H}_{2}$ and stirred at $80^{\circ} \mathrm{C}$ during $18 \mathrm{~h}$. The Fisher-Porter bottle was cooled down to room temperature and depressurized. The resulting black homogeneous solution of dispersed nanoparticles was dried under vacuum $(0.05 \mathrm{mmHg})$ at $80^{\circ} \mathrm{C}$ for $18 \mathrm{~h}$ to 
remove volatile organic compounds. The as-prepared $\mathrm{Rh}$ nanoparticles were characterized by TEM (see Figure S7 in the Supporting Information)

\section{Acknowledgements}

The Centre National de la Recherche Scientifique (CNRS) and the Université Toulouse 3 - Paul Sabatier are gratefully acknowledged for their financial support. The French-Mexican International Associated Laboratory "Laboratoire de Chimie Moléculaire avec applications dans les Matériaux et la Catalyse" (LCMMC) is acknowledged for financial support (project number 69-2018). The work was also supported by PhD fellowships to A. S. M. (CONACYT) and T. D.-B. (Ministry of Education and Training of the Socialist Republic of Vietnam and CNRS). The authors thank Christian Pradel for TEM analyses and Corinne Routaboul (ICT, Toulouse) for helpful assistance with the infrared experiments with the ReactIR.

Keywords: Hydroaminomethylation • Rhodium • Glycerol • Hydrogen transfer $\bullet$ Rh-catalyzed condensation

[1] a) M. B. Smith, March's advanced organic chemistry: reactions, mechanisms, and structure, John Wiley \& Sons, 2020; b) K. Eller, E. Henkes, R. Rossbacher, H. Höke, Ullmann's Encyclopedia of Industrial Chemistry 2000; c) D. Crozet, M. Urrutigoïty, P. Kalck, ChemCatChem 2011, 3, 1102

[2] For selected contributions, see: a) P. Kalck, M. Urrutigoïty, Chem. Rev. 2018, 118, 3833; b) T. Rische, P. Eilbracht, Synthesis 1997, 1997 1331; c) C. Chen, X.-Q. Dong, X. Zhang, Org. Chem. Front. 2016, 3, 1359; d) M.-N. Birkholz, Z. Freixa, P. W. van Leeuwen, Chem. Soc Rev. 2009, 38, 1099; e) X.-F. Wu, X. Fang, L. Wu, R. Jackstell, H. Neumann, M. Beller, Acc. Chem. Res. 2014, 47, 1041; f) J. F. Hartwig, Science 2002, 297, 1653; g) A. Behr, M. Fiene, C. Buß, P. Eilbracht Eur. J. Lipid Sci. Technol. 2000, 102, 467.

[3] a) T. Sperger, I. A. Sanhueza, I. Kalvet, F. Schoenebeck, Chem. Rev. 2015 115, 9532; b) O. Diebolt, P. W. N. M. van Leeuwen, P. C. J. Kamer ACS Catal. 2012, 2, 2357; c) M. Ahmed, A. M. Seayad, R. Jackstell, M. Beller, J. Am. Chem. Soc. 2003, 125, 10311.

[4] a) P. C. J. Kamer, A. van Rooy, G. C. Schoemaker, P. W. N. M. van Leeuwen, Coord. Chem. Rev 2004, 248, 2409; b) P. W. N. M. van Leeuwen, C. Claver, Rhodium Catalyzed Hydroformylation, Springer Netherlands, 2006; c) A. Börner, R. Franke, Hydroformylation: Fundamentals, Processes, and Applications in Organic Synthesis, Wiley, 2016; d) R. Franke, D. Selent, A. Börner, Chem. Rev. 2012, 112 5675 .

[5] B. Villa-Marcos, J. Xiao, Chin. J. Catal. 2015, 36, 106

[6] J. Meng, X.-H. Li, Z.-Y. Han, Org. Lett. 2017, 19, 1076

[7] a) J.-H. Xie, S.-F. Zhu, Q.-L. Zhou, Chem. Rev. 2011, 111, 1713; b) A Bartoszewicz, N. Ahlsten, B. Martín-Matute, Chem. Eur. J. 2013, 19, 7274; c) A. Baeza, A. Pfaltz, Chem. Eur. J. 2009, 15, 2266; d) G.-H. Hou, J.-H. Xie, P.-C. Yan, Q.-L. Zhou, J. Am. Chem. Soc. 2009, 131 1366.

[8] B. Zimmermann, J. Herwig, M. Beller, Angew. Chem. Int. Ed. 1999, 38, 2372.

[9] S. Hanna, J. C. Holder, J. F. Hartwig, Angew. Chem. Int. Ed. 2019, 58, 3368.

[10] Y. Wang, J. Chen, M. Luo, H. Chen, X. Li, Catal. Commun. 2006, 7, 979

[11] a) J. I. García, H. García-Marín, E. Pires, Green Chem. 2014, 16, 1007; b) A. E. Díaz-Álvarez, J. Francos, B. Lastra-Barreira, P. Crochet, V.
Cadierno, Chem. Commun. 2011, 47, 6208; c) A. E. Diaz-Alvarez, J. Francos, P. Croche, V. Cadierno, Curr. Green Chem. 2014, 1, 51; d) A Wolfson, C. Dlugy, Y. Shotland, Environ. Chem. Lett. 2007, 5, 67; e) A. Wolfson, C. Dlugy, Y. Shotland, D. Tavor, Tetrahedron Lett. 2009, 50, 5951.

[12] a) M. Rodríguez-Rodríguez, P. Llanes, C. Pradel, M. A. Pericàs, M Gómez, Chem. Eur. J. 2016, 22, 18247; b) C. Vidal, J. García-Álvarez, Green Chem. 2014, 16, 3515; c) F. Chahdoura, L. Dubrulle, K. Fourmy J. Durand, D. Madec, M. Gómez, Eur. J. Inorg. Chem. 2013, 2013 5138; d) A. Azua, J. A. Mata, E. Peris, F. Lamaty, J. Martinez, E. Colacino, Organometallics 2012, 31, 3911; e) A. E. Díaz-Álvarez, P Crochet, V. Cadierno, Catal. Commun. 2011, 13, 91.

[13] For selected reviews, see: a) I. Favier, D. Pla, M. Gómez, Chem. Rev. 2020, 120, 1146; b) F. Fiévet, S. Ammar-Merah, R. Brayner, F. Chau M. Giraud, F. Mammeri, J. Peron, J. Y. Piquemal, L. Sicard, G. Viau, Chem. Soc. Rev. 2018, 47, 5187; c) I. Favier, D. Pla, M. Gómez, Catal. Today 2018, 310, 98; d) T. Dang-Bao, D. Pla, I. Favier, M. Gómez, Catalysts 2017, 7, 207.

[14] a) T. Dang-Bao, C. Pradel, I. Favier, M. Gómez, ACS Appl. Nano Mater 2019, 2, 1033; b) A. Reina, A. Serrano-Maldonado, E. Teuma, E. Martin, M. Gómez, Catal. Commun. 2018, 104, 22; c) A. Reina, I. Favier, C. Pradel, M. Gómez, Adv. Synth. Catal. 2018, 360, 3544; d) T. Dang-Bao, C. Pradel, I. Favier, M. Gómez, Adv. Synth. Catal. 2017, 359, 2832; e) A. Reina, C. Pradel, E. Martin, E. Teuma, M. Gómez, RSC Adv. 2016, 6, 93205; f) F. Chahdoura, C. Pradel, M. Gómez, Adv. Synth. Catal. 2013, 355, 3648; g) F. Chahdoura, C. Pradel, M. Gómez, ChemCatChem 2014, 6, 2929; h) F. Chahdoura, I. Favier, C. Pradel, S. Mallet-Ladeira M. Gómez, Catal. Commun. 2015, 63, 47; i) F. Chahdoura, S. MalletLadeira, M. Gómez, Org. Chem. Front. 2015, 2, 312.

[15] M. Rodríguez-Rodríguez, E. Gras, M. A. Pericàs, M. Gómez, Chem. Eur. J. 2015, 21, 18706.

[16] J. A. Fuentes, P. Wawrzyniak, G. J. Roff, M. Bühl, M. L. Clarke, Catal. Sci. Technol. 2011, 1, 431

[17] a) A. de Oliveira Dias, M. G. P. Gutiérrez, J. A. A. Villarreal, R. L. L. Carmo, K. C. B. Oliveira, A. G. Santos, E. N. dos Santos, E. V. Gusevskaya, Appl. Catal., A 2019, 574, 97; b) B. Hamers, E. Kosciusko - Morizet, C. Müller, D. Vogt, ChemCatChem 2009, 1, 103.

[18] S. Tin, T. Fanjul, M. L. Clarke, Beilstein J. Org. Chem. 2015, 11, 622.

[19] a) Prepared as described in the following reference; b) W. Sucrow, $\mathrm{H}$. Minas, H. Stegemeyer, P. Geschwinder, H. R. Murawski, C. Krüger, Chem. Ber. 1985, 118, 3332.

[20] See the following reference for the non-catalyzed reduction of enamines by alcohols: A. Gilbert Cook, Tetrahedron Lett. 2010, 51, 3762.

[21] This assumption was confirmed by the reduction of 4-phenyl-3-buten-2 one by glycerol, which gave a mixture of 4-phenylbutan-2-one (reduction of $\mathrm{C}=\mathrm{C}$ ) and 4-phenylbutan-2-ol (reduction of both $\mathrm{C}=\mathrm{C}$ and $\mathrm{C}=\mathrm{O}$ ), thus predominating hydrogen transfer reactions over acetalization (see Figure $\mathrm{S} 2$ in the Supporting Information).

[22] a) X. Luo, D. Tang, M. Li, Int. J. Quantum Chem. 2006, 106, 1844; b) G. Alagona, R. Lazzaroni, C. Ghio, J. Mol. Model. 2011, 17, 2275; c) K Nozaki, T. Matsuo, F. Shibahara, T. Hiyama, Organometallics 2003, 22 594; d) C. Kubis, M. Sawall, A. Block, K. Neymeyr, R. Ludwig, A Börner, D. Selent, Chem. Eur. J. 2014, 20, 11921; e) M. Sparta, K. J. Børve, V. R. Jensen, J. Am. Chem. Soc. 2007, 129, 8487.

[23] For $\mathrm{Rh}(\mathrm{I})$ and $\mathrm{Rh}(\mathrm{III})$ complexes containing morpholine, see: a) M. G. L. Petrucci, A.-M. Lebuis, A. K. Kakkar, Organometallics 1998, 17, 4966 b) M. Beller, H. Trauthwein, M. Eichberger, C. Breindl, T. E. Müller, Eur. J. Inorg. Chem. 1999, 1999, 1121; c) M. Beller, H. Trauthwein, M. Eichberger, C. Breindl, J. Herwig, T. E. Müller, O. R. Thiel, Chem. Eur. J. 1999, 5, 1306; d) M. Schmidlehner, P.-S. Kuhn, C. M. Hackl, A Roller, W. Kandioller, B. K. Keppler, J. Organomet. Chem. 2014, 772773, 93.

[24] U. Gellrich, T. Koslowski, B. Breit, Catal. Sci. Technol. 2015, 5, 129

[25] a) S. Yu, Y.-m. Chie, Z.-h. Guan, Y. Zou, W. Li, X. Zhang, Org. Lett. 2009, 11, 241; b) S. Li, K. Huang, J. Zhang, W. Wu, X. Zhang, Org. Lett. 2013, 15,3078 . 


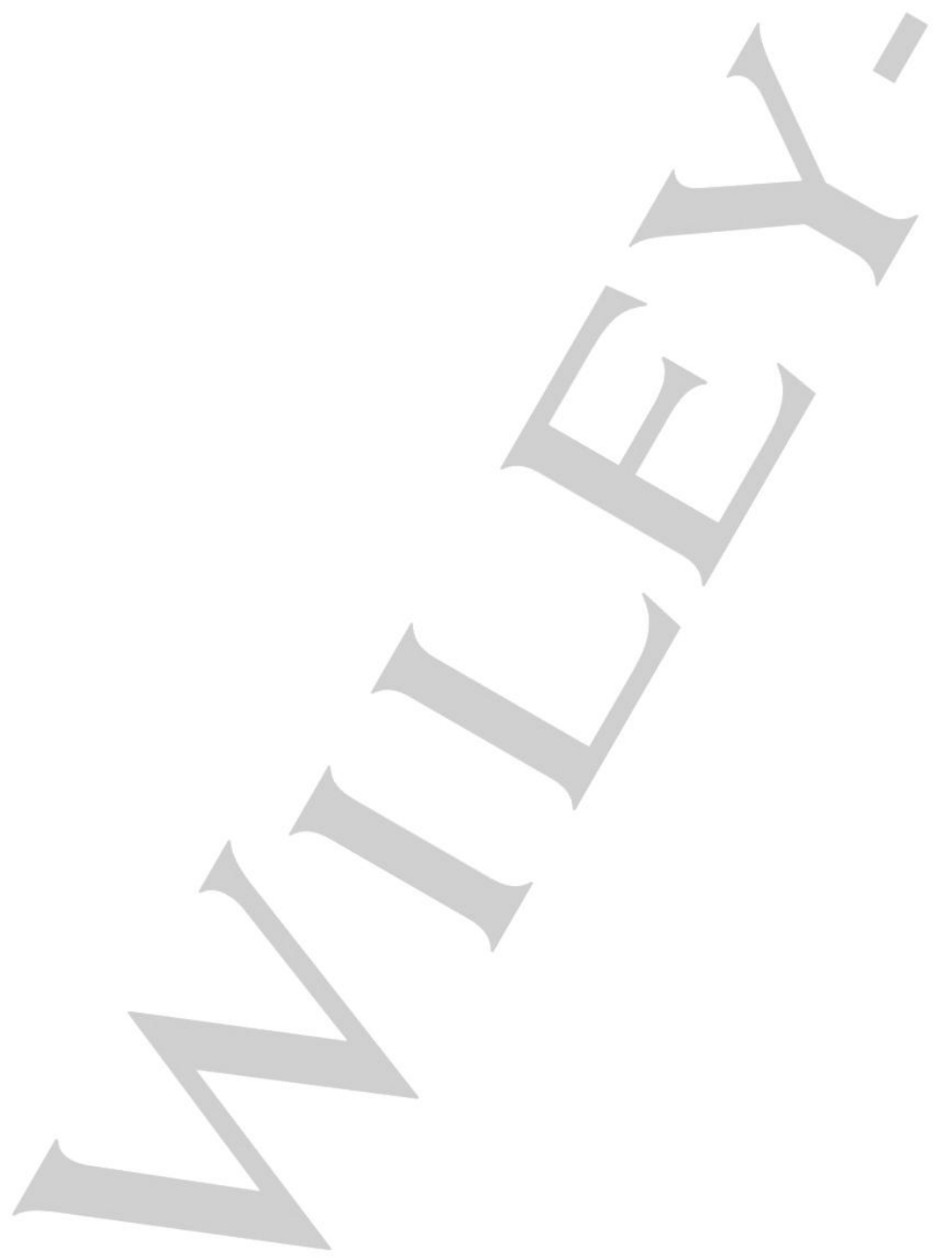




\section{Entry for the Table of Contents}

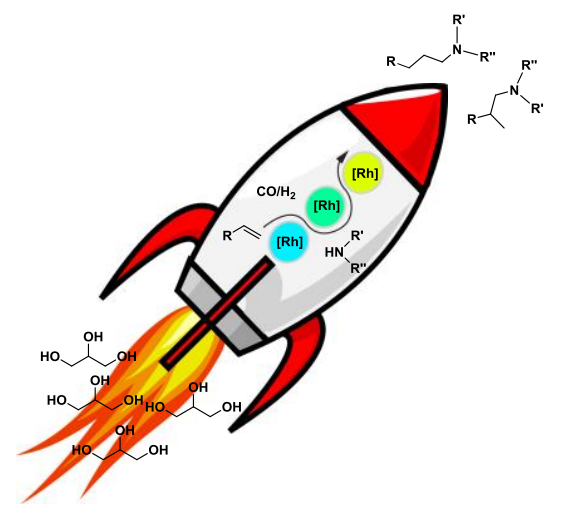

A multitalented monometallic Rh-based catalytic system in glycerol enables tandem hydroaminomethylation reaction under a molecular regime, via low pressure hydroformylation, Lewis acid-assisted condensation and enamine reduction boosted by hydrogen transfer.

Twitter: https://twitter.com/cat_tlse 